\title{
Global carbon tetrachloride distributions obtained from the Atmospheric Chemistry Experiment (ACE)
}

\author{
N. D. C. Allen ${ }^{1}$, P. F. Bernath ${ }^{1,2}$, C. D. Boone ${ }^{2}$, M. P. Chipperfield ${ }^{3}$, D. Fu ${ }^{2,4}$, G. L. Manney ${ }^{4,5}$, D. E. Oram ${ }^{6}$, \\ G. C. Toon ${ }^{4}$, and D. K. Weisenstein ${ }^{7}$ \\ ${ }^{1}$ Department of Chemistry, University of York, Heslington, York, YO10 5DD, UK \\ ${ }^{2}$ Department of Chemistry, University of Waterloo, Waterloo, Ontario, Canada \\ ${ }^{3}$ School of Earth and Environment, University of Leeds, Leeds, LS2 9JT, UK \\ ${ }^{4}$ Jet Propulsion Laboratory/California Institute of Technology, Pasadena, CA, USA \\ ${ }^{5}$ Department of Physics, New Mexico Institute of Mining and Technology, Socorro, NM, USA \\ ${ }^{6}$ School of Environmental Science, University of East Anglia, Norwich, NR4 7TJ, UK \\ ${ }^{7}$ Atmospheric and Environmental Research, Inc., Lexington, Massachusetts, USA
}

Received: 18 March 2009 - Published in Atmos. Chem. Phys. Discuss.: 17 June 2009

Revised: 17 September 2009 - Accepted: 18 September 2009 - Published: 7 October 2009

\begin{abstract}
The first study of the global atmospheric distribution of carbon tetrachloride $\left(\mathrm{CCl}_{4}\right)$, as a function of altitude and latitude, was performed using solar occultation measurements obtained by the Atmospheric Chemistry Experiment (ACE) mission using Fourier transform spectroscopy. A total of 8703 profile measurements were taken in the upper troposphere and lower stratosphere between February 2004 and August 2007. The zonal distribution of carbon tetrachloride displays a slight hemispheric asymmetry and decreasing concentration with increasing altitude at all latitudes. Maximum carbon tetrachloride concentrations are situated below $10 \mathrm{~km}$ in altitude with VMR (Volume Mixing Ratio) values of 100-130 ppt (parts per trillion). The highest concentrations are located about the Equator and at mid-latitudes, particularly for latitudes in heavily industrialised regions (20$45^{\circ} \mathrm{N}$ ), with values declining towards the poles. Global distributions obtained from ACE were compared with predictions from three chemistry transport models showing good agreement in terms of the vertical gradient despite an overall offset. The ACE dataset gives unique global and temporal coverage of carbon tetrachloride and its transport through the atmosphere. An estimated lifetime for carbon tetrachloride of $34 \pm 5$ years was determined through correlation with CFC-11.
\end{abstract}

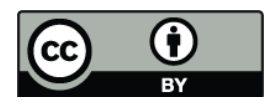

Correspondence to: N. D. C. Allen (ndca500@york.ac.uk)

\section{Introduction}

The synthesis of carbon tetrachloride $\left(\mathrm{CCl}_{4}\right.$, also known as tetrachloromethane) from chloroform and chlorine was first reported by Regnault in 1839 . Chemically inert, carbon tetrachloride was originally used as a fumigant, fire extinguisher and predominantly as a cleaning reagent or industrial solvent (Galbally, 1976; Altshuller, 1976). The chronic toxicity associated with carbon tetrachloride led to its replacement with less harmful solvents (Singh, 1976). Nevertheless with the growing consumption of chlorofluorocarbons (CFCs) in the 1950s, carbon tetrachloride became an important feedstock in the production of CFC-11 and CFC-12 (Simmonds et al., 1998). Despite the reduction in the use of carbon tetrachloride it is still a major component of the atmospheric chlorine budget. The contribution of carbon tetrachloride to the total chlorine budget for the troposphere was estimated to be $11 \%$ (World Meteorological Organisation (WMO), 2007). Using the total stratospheric chlorine budget of $3.65 \mathrm{ppb}$ derived by Nassar et al. (2006) it is estimated from ACE retrievals that carbon tetrachloride makes up approximately $3 \%$ of this value.

The main, if not sole, source of carbon tetrachloride is from anthropogenic emissions, although it has been suggested that there is a small biogenic component (Lovelock and Maggs, 1973; Butler et al., 1999). However attempts to reconstruct an atmospheric history have proven inconclusive (Sturrock et al., 2002). Due to its longevity in the atmosphere it is believed that the main sink mechanism for carbon tetrachloride is through photochemical destruction (R1 and

Published by Copernicus Publications on behalf of the European Geosciences Union. 
R2) in the stratosphere (Galbally, 1976). The ocean (Lovelock and Maggs, 1973; Yvon-Lewis and Butler., 2002) and soil (Happell and Roche, 2003) are thought to be additional less significant sinks. The loss of carbon tetrachloride caused by ocean uptake and hydrolysis reduced the estimated atmospheric lifetime of carbon tetrachloride from 35 to 26 years (WMO, 1999, 2003).

$$
\begin{aligned}
& \mathrm{CCl}_{4}+h v \rightarrow \mathrm{CCl}_{3}+\mathrm{Cl} \\
& \mathrm{CCl}_{4}+h v \rightarrow \mathrm{CCl}_{2}+\mathrm{Cl}_{2} \\
& \mathrm{O}\left({ }^{1} \mathrm{D}\right)+\mathrm{CCl}_{4} \rightarrow \text { products }
\end{aligned}
$$

Following concerns over the catalytic destruction of ozone by chlorine-containing species (Molina and Rowland, 1974) estimates of global emissions of carbon tetrachloride have been attempted (Galbally, 1976; Simmonds et al., 1988, 1998; Singh, 1976), although poor industrial records and an underestimation of emissions in Asia (Palmer et al., 2003) and other parts of the world have led to significant levels of uncertainty. The discovery of the ozone hole by the British Antarctic Survey (Farman et al., 1985) led to compounds with high ozone depleting potentials (ODPs), such as carbon tetrachloride, being phased out through the implementation of the Montreal Protocol (The Montreal Protocol on Substances that Deplete the Ozone Layer and its Amendments and Adjustments, 1987) and its amendments.

Carbon tetrachloride is a potent greenhouse gas with a global warming potential (GWP) of 1400 , relative to $\mathrm{CO}_{2}$ which has a GWP of 1 , on a 100 year time horizon (Solomon et al., 2007). As carbon tetrachloride is a relatively shortlived chlorine-containing compound compared to CFCs, the reduction of approximately $1 \%$ a year since the early $1990 \mathrm{~s}$ in surface level concentrations has had a considerable effect in reducing anthropogenic radiative forcing by approximately $1.1 \times 10^{-5} \mathrm{~W} \mathrm{~m}^{-2}$ per year (Foster et al., 2007). Surprisingly the Montreal Protocol has already had a greater effect on climate protection than that of the first commitment period of the Kyoto Protocol (Velders et al., 2007).

Using gas chromatography (GC) the first atmospheric measurements of carbon tetrachloride were taken by Lovelock and Maggs (1973) over the Atlantic. Since 1978 the Advanced Global Atmospheric Gases Experiment (AGAGE) and its predecessors have made continuous ground based in situ measurements (Prinn et al., 2000) from clean sea air at five locations. NASA's intensive airborne measurement campaigns over the Pacific, including Pacific Exploratory Mission (PEM) West A and B, as well as the Transport and Chemical Evolution over the Pacific (TRACE-P) in 1991, 1994 and 2001, respectively, sampled carbon tetrachloride evolution and transport at altitudes below $12 \mathrm{~km}$ (Blake et al., 1996, 2003). In situ GC measurements taken on board the ER-2 aircraft (Elkins et al., 1996; Romashkin et al., 2000) have compared carbon tetrachloride concentrations with reported GC measurements taken on seven balloon flights between $7^{\circ} \mathrm{S}$ and $67^{\circ} \mathrm{N}$ (Moore et al., 2003) from 1996 to
2000 and one MkIV balloon flight using FTS (Fourier transform spectroscopy) at $65^{\circ} \mathrm{N}$ (Toon et al., 1999). ATMOS (Atmospheric Trace MOlecule Spectroscopy) volume mixing ratio (VMR) profiles for carbon tetrachloride between $30^{\circ} \mathrm{N}$ and $51^{\circ} \mathrm{N}$ taken using a Fourier transform spectrometer (FTS) on the ATLAS-3 Space Shuttle Mission in November 1994 were also compared with ER-2 aircraft data (Chang et al., 1996). Stratospheric measurements were reported using Cryogenic Infrared Radiance Instrumentation (CIRRIS1A) during a short space mission (Zhou et al., 1998). However there has been a lack of stratospheric and global measurements. To the best of our knowledge, there have been no prior reports of a global distribution of carbon tetrachloride using satellite data.

\section{Observations and retrievals}

The Atmospheric Chemistry Experiment (ACE), also referred to as SCISAT, is a Canadian satellite used for remote sensing of trace gases in the Earth's atmosphere from a low circular orbit (altitude $650 \mathrm{~km}$, inclination $74^{\circ}$ ). The primary instrument on the ACE satellite is a high-resolution Fourier transform spectrometer (FTS) with coverage of the 750 to $4400 \mathrm{~cm}^{-1}$ spectral region. The spectrometer has a $0.02 \mathrm{~cm}^{-1}$ spectral resolution with a maximum optical path difference of $\pm 25 \mathrm{~cm}$ (Bernath et al., 2005). The ACE-FTS records spectra by solar occultation. The sun tracker locks onto the centre of the sun whilst a set of transmission spectra are taken through the limb of the Earth's atmosphere during sunrise and sunset. VMR profiles of trace species from the mid-troposphere through to the lower thermosphere, along with temperature and pressure profiles, are retrieved from the set of transmission spectra (Boone et al., 2005). Over 30 trace species are retrieved from ACE-FTS spectra, including multiple isotopologues for some species, with a vertical resolution of 3-4 km.

The current retrieval version for the ACE-FTS is version 2.2; however carbon tetrachloride is not reported in the official version 2.2 results. The data employed here are from a "research processing" dataset generated using the ACE-FTS analysis software. The retrieval window for carbon tetrachloride is centered at $796.5 \mathrm{~cm}^{-1}$ and is $18 \mathrm{~cm}^{-1}$ wide. The altitude range of the retrieval varies as a function of latitude, extending from 7 to $30 \mathrm{~km}$ at the Equator and 6 to $25 \mathrm{~km}$ at the poles. Treating different isotopologues of a given molecule as separate interferers (with each isotopologue having a different VMR profile) there are a total of 13 interferers in the retrieval of carbon tetrachloride. These interferers are $\mathrm{H}_{2} \mathrm{O}$ isotopologues $\mathrm{H}_{2}^{16} \mathrm{O}, \mathrm{H}_{2}^{18} \mathrm{O}$ and $\mathrm{H}_{2}^{17} \mathrm{O}, \mathrm{CO}_{2}$ isotopologues ${ }^{12} \mathrm{C}^{16} \mathrm{O}_{2},{ }^{13} \mathrm{C}^{16} \mathrm{O}_{2}$ and ${ }^{12} \mathrm{C}^{16} \mathrm{O}^{18} \mathrm{O}, \mathrm{O}_{3}, \mathrm{HO}_{2} \mathrm{NO}_{2}, \mathrm{ClONO}_{2}$, $\mathrm{C}_{2} \mathrm{H}_{6}, \mathrm{C}_{2} \mathrm{H}_{2}$, and HCFC-22. Additional microwindows are used to improve the retrieval results for the following interferers: $\mathrm{H}_{2} \mathrm{O}$ isotopologues $\mathrm{H}_{2}^{18} \mathrm{O}$ and $\mathrm{H}_{2}^{17} \mathrm{O}, \mathrm{CO}_{2}$ isotopologues ${ }^{13} \mathrm{C}^{16} \mathrm{O}_{2}$ and ${ }^{12} \mathrm{C}^{16} \mathrm{O}^{18} \mathrm{O}, \mathrm{ClONO}_{2}, \mathrm{C}_{2} \mathrm{H}_{6}, \mathrm{C}_{2} \mathrm{H}_{2}$, 


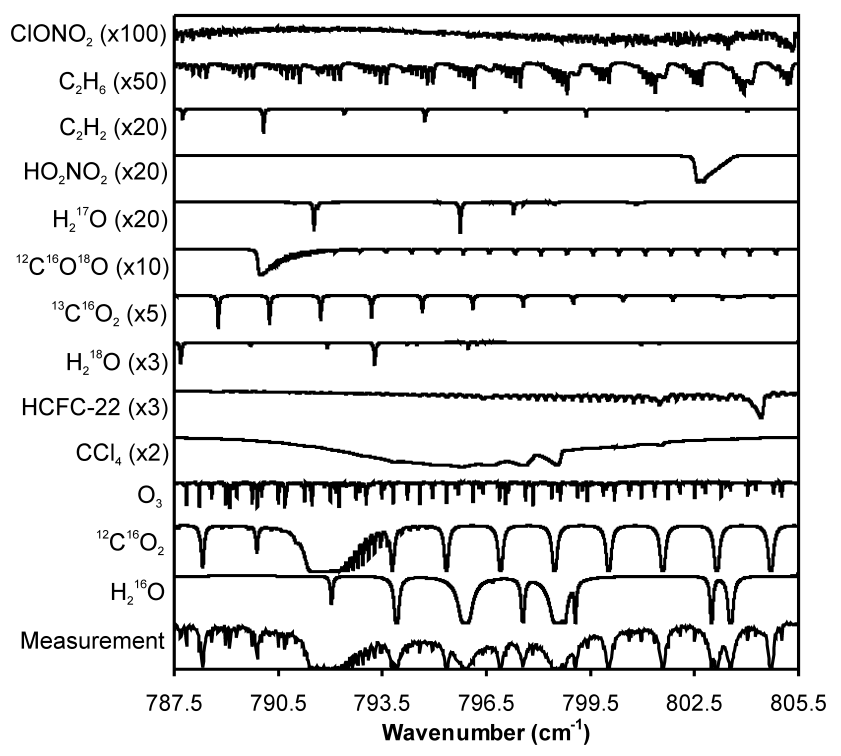

Fig. 1. The species which contribute to the spectral window in which carbon tetrachloride is retrieved. Weaker absorbers have been magnified and the baseline is offset in the vertical direction for clarity. The plot corresponds to the measurement (bottom panel) at a tangent height of $8.3 \mathrm{~km}$ in tropical occultation ss 11613 .

and HCFC-22. Spectroscopic parameters for the interferer $\mathrm{HO}_{2} \mathrm{NO}_{2}$ were obtained using pseudo-lines from the ATMOS line list (Brown et al., 1996). Cross section data for $\mathrm{ClONO}_{2}, \mathrm{HCFC}-22$, and $\mathrm{CCl}_{4}$, along with line parameters for all the other interferers in the microwindow, were obtained from the HITRAN 2004 dataset (Rothman et al., 2005).

There is clear evidence of line mixing in a $\mathrm{CO}_{2}$ Q-branch contained in the $\mathrm{CCl}_{4}$ microwindow (Kochel et al., 1997), but this is not included in the forward model calculation and is simply neglected. Taking a small sample of 15 occultations (sr10899-sr10943) line mixing was included (based on parameters determined for a single occultation ss11613) to estimate the effect on the Q-branch. The results showed an average reduction in the residuals, and the VMRs decreased by $3-5 \%$ above $10 \mathrm{~km}$ and $10 \%$ above $20 \mathrm{~km}$ where the concentration is lower. For a tropical occultation ss 11613 at $8.3 \mathrm{~km}$ a plot of the species which contribute to the window in which carbon tetrachloride is retrieved are shown (Fig. 1). In Fig. 1 $\mathrm{ClONO}_{2}$ is weak and has a much stronger absorption in the stratosphere and in the polar regions. The statistical errors in the retrieval below $15 \mathrm{~km}$ remain low at the typical value of $5 \%$, but the systematic errors can grow to $20-30 \%$. The systematic error in the cross section data (Nemtchinov and Varanasi, 2003) used in our retrievals is estimated to be as large as $10 \%$. In the troposphere the major error is the systematic error in the retrieval with minor contributions from the error in the cross sections and the statistical retrieval error. In the stratosphere, the systematic retrieval error is rela-

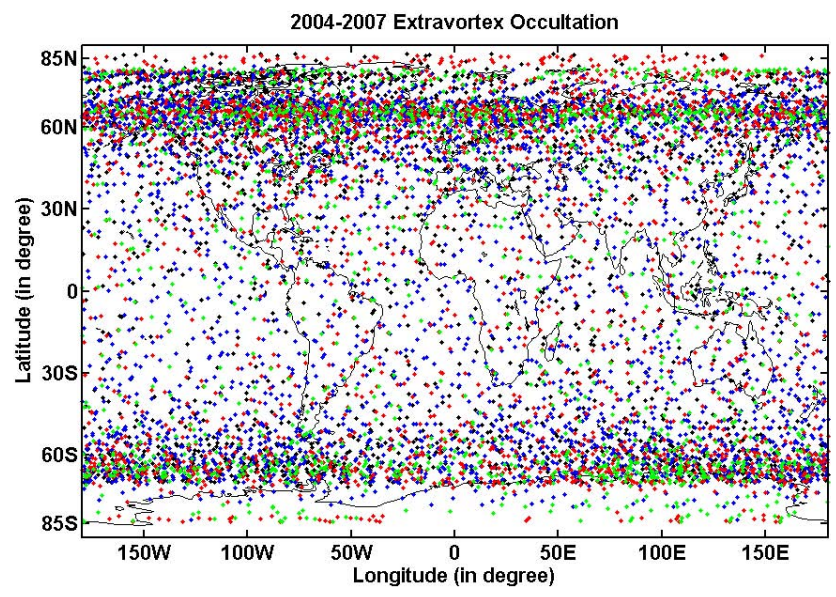

Fig. 2. The locations of 8703 extravortex ACE-FTS occultations during the period February 2004 to August 2007 are indicated by coloured markers. Each colour denotes a different year; black: 2004, blue: 2005, red: 2006 and green: 2007.

tively small, the cross section error remains the same, but the statistical retrieval error now dominates.

In polar winter and spring the VMRs of chemical species such as carbon tetrachloride are low as a result of descent within the polar vortex. Occultation measurements taken by ACE inside the polar vortex or at the vortex edge have therefore been excluded. The 10978 occultation measurements taken by ACE between February 2004 and August 2007 were filtered using the derived meteorological products (DMPs) classified using potential vorticity values (Manney et al, 2007) obtained from Met Office data (Swinbank and O'Neill, 1994; Swinbank et al., 2002; Davies et al., 2005), in a similar approach to that adopted by Nassar et al. (2005), 2275 profiles were classified as within or on the edge of the polar vortex and were discarded, while 8703 were classified as extravortex occultations. The geographic distribution of ACE sampling is shown in Fig. 2.

\section{Results and discussion}

Data starting at $90^{\circ} \mathrm{S}$ and ending at $90^{\circ} \mathrm{N}$ were separated into 36 equal latitude zones with a width of five degrees; six bins $\left(90^{\circ} \mathrm{S}-70^{\circ} \mathrm{S}\right.$ and $\left.80^{\circ} \mathrm{N}-90^{\circ} \mathrm{N}\right)$ were removed in the polar regions due to the small number of extravortex occultations. An average profile was calculated for each latitude bin. Carbon tetrachloride has a lifetime estimated to be approximately 26 years (WMO, 2007) and ground based measurements show a slight seasonal cycle (Prinn et al., 2000). The 2006 WMO report estimates that the surface concentration of carbon tetrachloride is declining at a rate of $1 \pm 0.1 \mathrm{ppt}$ year $^{-1}$. ACE measurements have been averaged over the February 2004 to August 2007 time period to obtain a global distribution. A contour plot of the global distribution was 


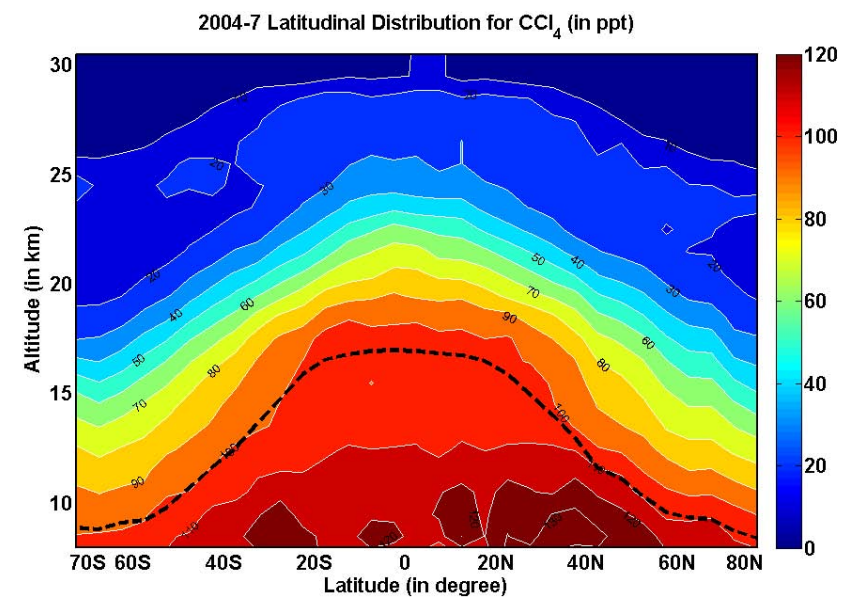

Fig. 3. A near global distribution of the average volume mixing ratio of carbon tetrachloride (in ppt) as a function of latitude between 8 and $30 \mathrm{~km}$ altitude obtained from ACE-FTS profiles from February 2004 and August 2007 is depicted. The average tropopause height is marked with a dashed black line. The data is taken from the DMPs for each occultation and then averaged for each latitude bin, as with the carbon tetrachloride measurements.

created using the VMR data for the 30 averaged bins spanning the latitudes $70^{\circ} \mathrm{S}$ to $80^{\circ} \mathrm{N}$ between the altitudes of 8 and $30 \mathrm{~km}$. The data for the 30 average bins is provided in supplementary Table $1 \mathrm{http}: / /$ www.atmos-chem-phys.net/9/ 7449/2009/acp-9-7449-2009-supplement.pdf, with the number of measurements used for the average bins provided in supplementary Table $3 \mathrm{http}: / /$ www.atmos-chem-phys.net/9/ 7449/2009/acp-9-7449-2009-supplement.pdf.

The global distribution for carbon tetrachloride, shown in Fig. 3 as a contour map, is nearly symmetric about the Equator. There is a general trend that the VMR monotonically decreases as a function of altitude; concentrations decline towards the poles. Carbon tetrachloride is emitted into the troposphere, and this is where the highest VMR values between 100 and $130 \mathrm{ppt}$ are observed. The greatest concentrations corresponded to latitudes that encompass major industrial regions $\left(20-50^{\circ} \mathrm{N}\right)$. Lower stratospheric concentrations are significantly higher between $20^{\circ} \mathrm{S}$ and $20^{\circ} \mathrm{N}$ compared to higher latitudes where mixing ratios are $20-40 \mathrm{ppt}$ lower. This pattern can be attributed to the Brewer-Dobson circulation and the general appearance is typical of long lived gases such as CFCs that have surface sources and are destroyed in the stratosphere. In the stratosphere there is a decline in the VMR of carbon tetrachloride, which becomes negligible above $25 \mathrm{~km}$ in the polar latitudes and $28 \mathrm{~km}$ in the latitudes near the Equator, corresponding to altitudes close to the detection limit. The drop in concentration is consistent with transport and photochemical destruction in the stratosphere. There is some asymmetry at higher latitudes with lower mixing ratios observed at southern latitudes compared to the equivalent northern latitudes. This can be attributed

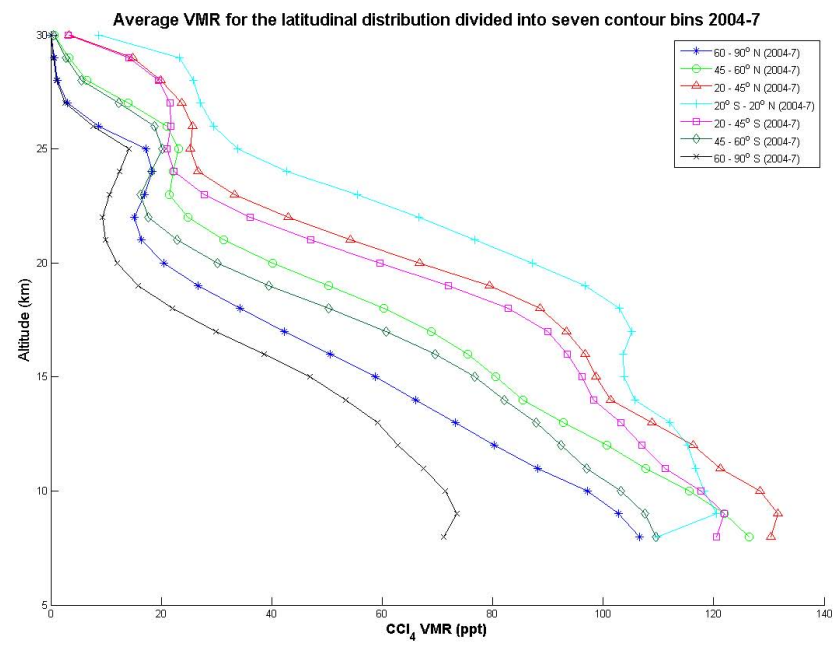

Fig. 4. The average volume mixing ratio (in ppt) from ACE-FTS profiles spanning February 2004 to August 2007 for seven zonal regions: $60-90^{\circ} \mathrm{S}$ (black line with crosses), $45-60^{\circ} \mathrm{S}$ (dark green line with diamonds), $20-45^{\circ} \mathrm{S}$ (magenta line with squares), $20^{\circ} \mathrm{S}-$ $20^{\circ} \mathrm{N}$ (cyan line with plus signs), $20-45^{\circ} \mathrm{N}$ (red line with triangles), $45-60^{\circ} \mathrm{N}$ (light green line with circles) and $60-90^{\circ} \mathrm{N}$ (blue line with asterisks) are compared and displayed with respect to altitude between 8 to $30 \mathrm{~km}$. Polar measurements were not retrieved above $25 \mathrm{~km}$ whilst in the tropics retrievals were made up to $30 \mathrm{~km}$. A priori profiles have been spliced on above the maximum retrieved value so all curves reach $30 \mathrm{~km}$; high altitude peaks near $25 \mathrm{~km}$ are artifacts.

to the smaller emissions in the Southern Hemisphere despite interhemispheric transport.

To identify hemispheric differences in VMR, the extravortex occultations were divided into seven different latitude zones $\left(60-90^{\circ} \mathrm{S}, 45-60^{\circ} \mathrm{S}, 20-45^{\circ} \mathrm{S}, 20^{\circ} \mathrm{S}-\right.$ $20^{\circ} \mathrm{N}, 20-45^{\circ} \mathrm{N}, 45-60^{\circ} \mathrm{N}$ and $\left.60-90^{\circ} \mathrm{N}\right)$ and an average VMR for each zone was determined (supplementary Table 2 http://www.atmos-chem-phys.net/9/7449/2009/ acp-9-7449-2009-supplement.pdf). The VMR average for each zone was then plotted as a function of altitude, as shown in Fig. 4. In the mid and lower stratosphere carbon tetrachloride VMRs show little difference between the corresponding southern and northern hemispheric zones. The greatest decline in the concentration of carbon tetrachloride, as a function of altitude, is observed in the zones closest to the poles $\left(60-90^{\circ} \mathrm{S}\right.$ and $\left.60-90^{\circ} \mathrm{N}\right)$. Above the troposphere concentrations are greatest in the equatorial zone $\left(20^{\circ} \mathrm{S}-20^{\circ} \mathrm{N}\right)$ at all altitudes. Tropospheric VMR values are higher between $20^{\circ} \mathrm{N}$ and $60^{\circ} \mathrm{N}$ consistent with emission predominantly in the Northern Hemisphere. The overall pattern is consistent with carbon tetrachloride having a long chemical lifetime with destruction in the stratosphere.

The majority of carbon tetrachloride measurements have been taken at ground level or from aircraft in the troposphere and the lower stratosphere. Prinn et al. (2000) 


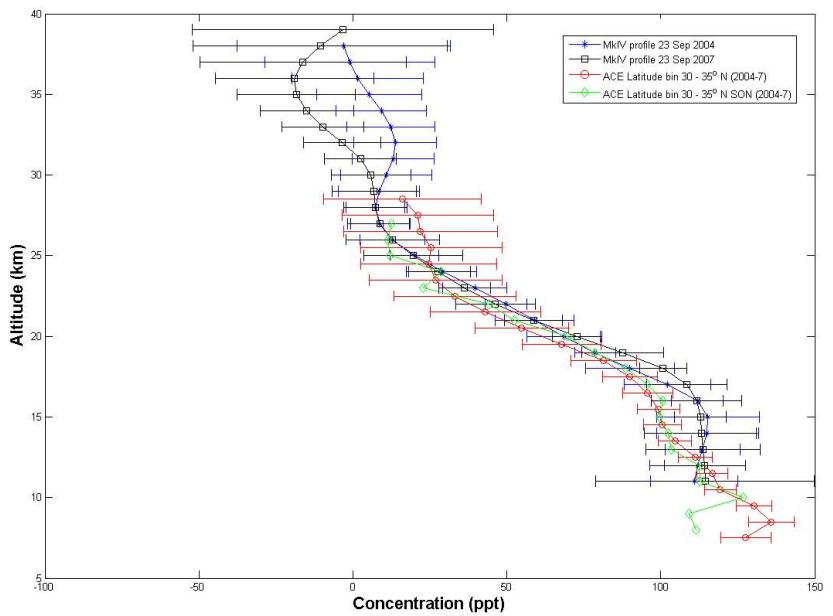

Fig. 5. The average carbon tetrachloride volume mixing ratio profile for the latitude bin $30-35^{\circ} \mathrm{N}$ (red line with circles), as well as the seasonal SON (September-October-November) latitude bin (green line with diamonds) for the same region $\left(30-35^{\circ} \mathrm{N}\right)$, from the ACE mission between February 2004 and August 2007 is displayed and compared with two balloon profiles from near Ft. Sumner, New Mexico $\left(33-35^{\circ} \mathrm{N}\right)$ obtained by Toon et al. (unpublished data) using a MkIV FTS instrument on the 23 September 2004 (blue line with asterisks) and 23 September 2007 (black line with squares).

reported carbon tetrachloride concentrations at ground level had declined from approximately 102-113 ppt in 1990 to 97-100 ppt by June 1998 at the five global AGAGE sites. However a reconstructed history of carbon tetrachloride up to the year 2000 from polar firn (unconsolidated snow) air estimated concentrations to be over $100 \mathrm{ppt}$ (Butler et al., 1999; Martinerie et al., 2009). Comparison of PEM West B and TRACE-P aircraft campaign data showed a decrease in the VMR of carbon tetrachloride over the Pacific from 107108 ppt in 1994 to $100-99$ ppt in 2001. The 2006 WMO report cited the global average concentration of carbon tetrachloride as $94.6 \mathrm{ppt}$ in 2004, dropping at a rate of approximately $1.0 \mathrm{ppt} \mathrm{yr}^{-1}$. Our remote sensing observations show considerable variation in tropospheric concentrations at $8 \mathrm{~km}$ from about $100 \mathrm{ppt}$ near the poles to as high as $130 \mathrm{ppt}$ at northern mid-latitudes. These high tropospheric values and ACE data errors are discussed below.

Balloon measurements allow comparison of vertical profiles with ACE data over a wide range of altitudes, including measurements in the stratosphere. The JPL MkIV interferometer (Toon, 1991) is a balloon-borne solar occultation FTS, similar to ACE. The MkIV has performed 21 balloon flights since 1989, each covering altitudes from the cloud tops (unable to retrieve through opaque clouds) to the float ceiling altitude which the balloon payload can reach (35$40 \mathrm{~km})$ at $2-4 \mathrm{~km}$ vertical resolution. The $\mathrm{MkIV} \mathrm{CCl}_{4}$ retrievals use the same absorption band as ACE, and also ignore line mixing from the $\mathrm{CO}_{2}$ Q-branch. Toon et al. (1999)

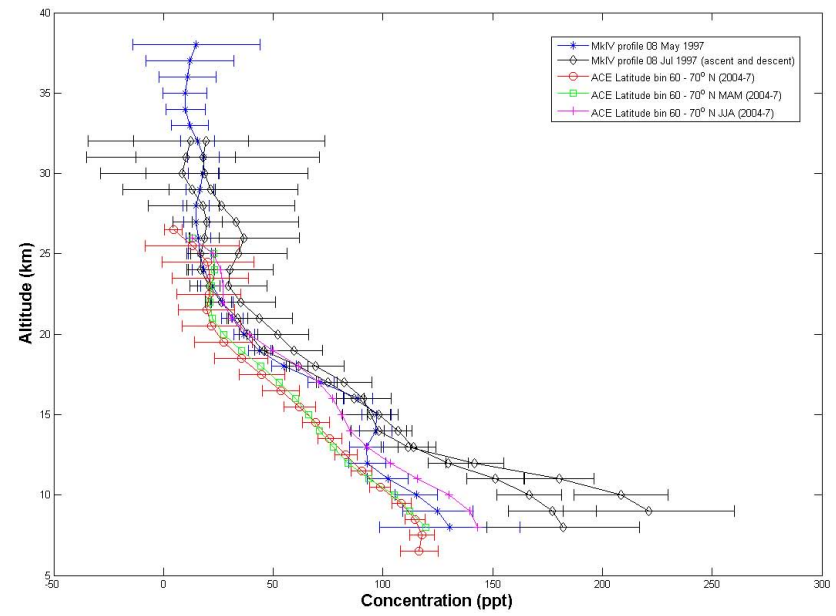

Fig. 6. The average carbon tetrachloride volume mixing ratio profile for the latitude bin covering $60-70^{\circ} \mathrm{N}$ (red line with circles) from the ACE mission between February 2004 and August 2007. The average profile is compared with three balloon profiles obtained using the MkIV FTS instrument launched from Fairbanks, Alaska (64$70^{\circ} \mathrm{N}$ ) on the 8 May 1997 (blue line with asterisks) and 8 July 1997 (ascent and descent both black lines with diamonds) obtained by Toon et al. (1999). The average profile, covering the same latitudes for the whole mission period, for the MAM (March-April-May) and JJA (June-July-August) seasons are also included (green line with squares and magenta line with pluses respectively).

fitted pseudo-lines to the Nemtchinov and Varanasi cross sections (2003) and used these in the MkIV retrieval. In Fig. 5, 6 and 7 MkIV balloon FTS measurements are displayed (Toon et al., 1999). These were taken during a number of campaigns at Ft. Sumner, New Mexico (33-35 N), Fairbanks, Alaska $\left(64-70^{\circ} \mathrm{N}\right)$ and Esrange, Sweden $\left(62-70^{\circ} \mathrm{N}\right)$. Carbon tetrachloride profiles at the three locations were compared with the average ACE VMR profile of the latitude bin corresponding to the latitude of the balloon flights (Figs. 57).

Measurements obtained from balloon launches in Ft. Sumner, New Mexico (Fig. 5) have very similar VMR profiles compared with ACE measurements (including the September-October-November seasonal average) and generally agree within measurement error. The New Mexico profiles decline at a similar rate to the average ACE profiles from the appropriate latitude bin. The majority of MkIV measurements cease at $11 \mathrm{~km}$, with VMRs of $120 \mathrm{ppt}$ in agreement with values from ACE (Fig. 3). In measurements taken over Fairbanks, Alaska (Fig. 6), all of the MkIV balloon profiles show good agreement with ACE retrievals in the stratosphere but there is a large discrepancy at tropospheric altitudes for the ascent and descent profiles measured on 8 July 1997. The temporal lag between the MkIV measurements at Fairbanks and the ACE retrievals mean that some variation would be expected between profiles. Average seasonal ACE profiles for the summer months (June, July and August) show a close 


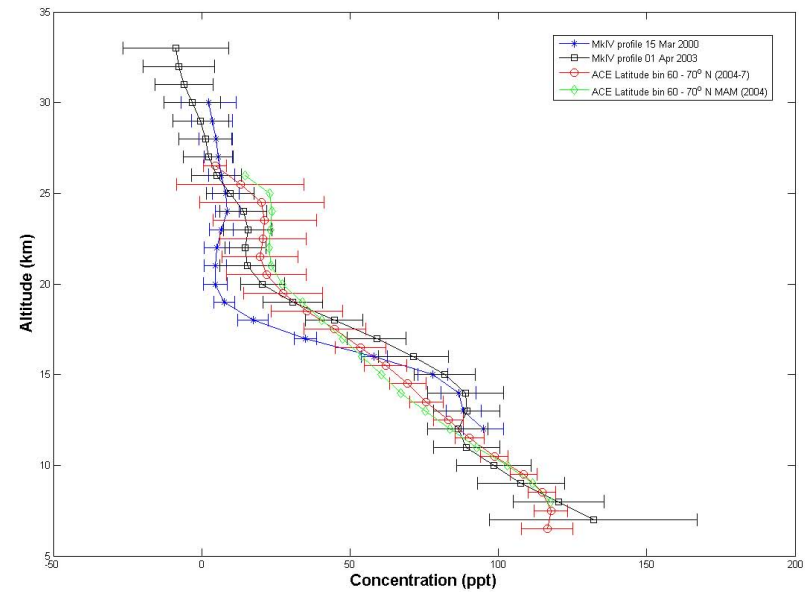

Fig. 7. The average carbon tetrachloride volume mixing ratio profile for the latitude bin covering $60-70^{\circ} \mathrm{N}$ (red line with circles) from the ACE mission between February 2004 and August 2007 is displayed. The average seasonal profile for MAM (March-AprilMay) over the $60-70^{\circ} \mathrm{N}$ latitude bin (green line with diamonds) is included solely for 2004. These average profiles are compared with two balloon profiles from near Esrange, Sweden $\left(62-70^{\circ} \mathrm{N}\right)$, obtained by Toon et al. (unpublished data) using the MkIV FTS instrument on the 15 March 2000 (blue line with asterisks) and 1 April 2003 (black line with squares).

resemblance to the profile for the balloon flight of the 8 May 1997. However, the agreement is not good for the 8 July 1997 flight; the large values and large error bars for this MkIV profile suggest that there is a problem with the retrieval.

The magnitude of systematic errors at low altitude is greatest using solar occultation technique. The measurements from Esrange, Sweden (Fig. 7) have VMRs that decrease more rapidly at stratospheric altitudes compared with ACE and other MkIV profiles. The more rapid decline in the lower stratospheric VMR of carbon tetrachloride in the balloon profiles can be attributed to the fact that the measurements were carried out in spring and are influenced by descent in the polar vortex, whilst the ACE zonal means are an average of extravortex profiles. In general there is good agreement between the MkIV balloon profiles and ACE data, especially in the stratosphere however in the lower troposphere there is considerable variation. The 2004 March-April May seasonal average is very similar to the overall average ACE profile. The MkIV and ACE profiles agree moderately well within the troposphere apart from the measurements taken over Fairbanks.

The CARIBIC (Civil Aircraft for the Regular Investigation of the atmosphere Based on an Instrument Container) programme makes regular measurements of trace gases and aerosols in the upper troposphere and lower stratosphere during long haul flights of a commercial airliner between Germany and destinations such as China, India and South America (Brenninkmeijer et al., 1999, 2007). Carbon tetrachloride is one of the many species measured in the 28 whole air samples that are collected during each flight. From samples collected between October 2006 and September 2008 in the Northern Hemisphere, the average VMR between 8 and $9 \mathrm{~km}$ was of $92 \mathrm{ppt}$, dropping to $85 \mathrm{ppt}$ at $12 \mathrm{~km}$. In contrast with ACE the CARIBIC data showed little latitude dependence. The CARIBIC data are reported on the NOAA 2002 calibration scale and are consistent with surface observations made with similar techniques. These measurements highlight the significant difference in absolute concentrations obtained by GC methods and FTS instruments such as ACE and the MkIV.

ACE retrievals appear to give an overestimate of the carbon tetrachloride concentration in the troposphere as compared to surface values (e.g. Montzka et al., 1999) due to the inherent difficulties in low altitude retrievals for limb viewing instruments. At low altitude the spectra become very complex and there are significant, systematic features in the fitting residuals that grow larger as you move to lower altitude. These include large residuals from $\mathrm{H}_{2} \mathrm{O}$ lines in the spectral window (Boone et al., 2007) and residuals from neglecting line-mixing for the $\mathrm{CO}_{2} \mathrm{Q}$-branch in the window. However, the magnitude of these errors is difficult to estimate.

The global distribution of carbon tetrachloride has been compared to calculations from three atmospheric models: The AER 2-D model (Weisenstein et al., 1997; Weisenstein et al., 2007), the GMI 3-D chemical transport model (CTM) (Strahan et al., 2007) and the SLIMCAT 3-D CTM (Chipperfield 1999; Feng et al., 2007). All of the model runs used surface carbon tetrachloride mixing ratios from WMO (2007) as the lower boundary condition. These mixing ratios decrease, for example, from $98.7 \mathrm{ppt}$ in January 2000 to 93.9 ppt in January 2005. In the models carbon tetrachloride has a very long lifetime in the troposphere and the imposed surface mixing ratios are well-mixed. In the stratosphere the models destroy carbon tetrachloride by photolysis and by reaction with $\mathrm{O}\left({ }^{1} \mathrm{D}\right.$ ) at a rate of $3.3 \times 10^{-10}$ (Sander et al., 2006). The predicted stratospheric distribution therefore depends to a large extent on the model stratospheric circulation. Stratospheric models are known to exhibit large differences with respect to each other and to observations for this circulation. In particular, in the past models have calculated a circulation which is too strong, leading to an age-ofair which is too young. For the runs shown here the GMI model (horizontal resolution $2^{\circ} \times 2.5^{\circ}$ and 42 levels from surface to $0.0158 \mathrm{hPa}$ ) was forced with six-hourly averaged GEOS4DAS winds. These produce a much better circulation than previous instantaneous GEOS4 winds. The SLIMCAT CTM run (horizontal resolution $5.6^{\circ} \times 5.6^{\circ}$ and 32 levels from surface to $\sim 0.1 \mathrm{hPa}$ ) was forced with European Centre for Medium Range Weather Forecasts analyses and used an isentropic vertical coordinate. Vertical transport in the stratosphere was diagnosed from calculated heating rates. This approach also gives a good representation of the stratospheric age-of-air (see Chipperfield 2006). The AER 2-D model (horizontal resolution 9.5 degrees and vertical resolution of 

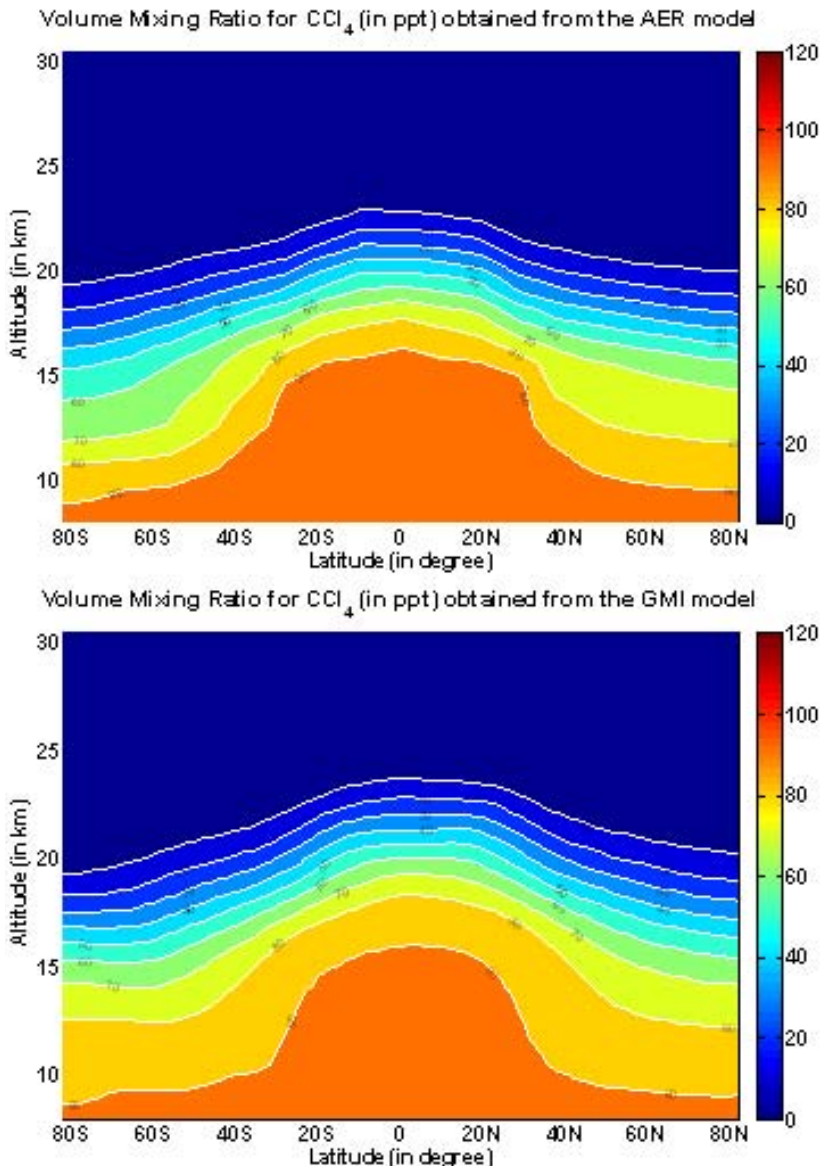

Volume Mxing Ratio for $\mathrm{CCl}_{4}$ (in ppt) obtained from the SL IMCAT model

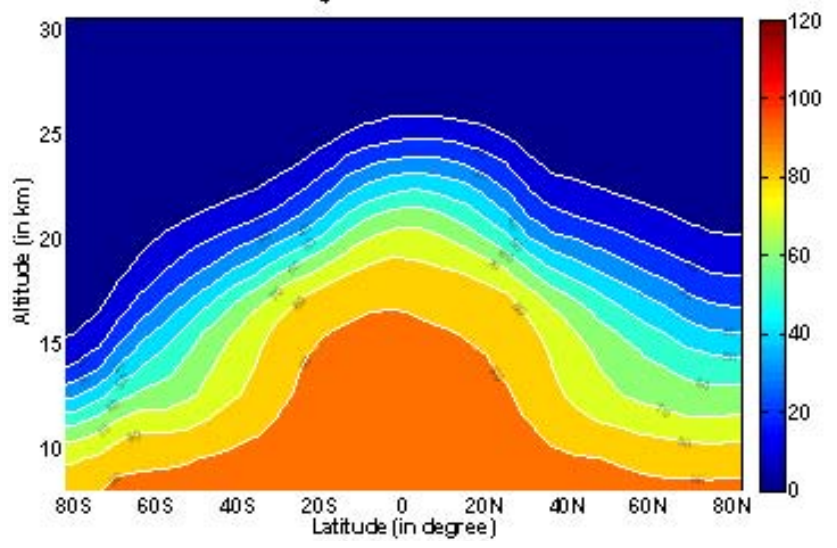

Fig. 8. The zonal mean annual mean latitude-height distribution of carbon tetrachloride VMR (ppt) from (a) the AER 2-D model, (b) the GMI 3-D model and (c) the SLIMCAT 3-D model.

$1.2 \mathrm{~km}$ from the surface to $0.02 \mathrm{hPa}$ ) used a climatological residual circulation from Fleming et al. (1999) but temperature and aerosol surface area matching the model year.

Figure 8 shows the zonal mean distribution of carbon tetrachloride calculated by the three models averaged over the period of ACE observations. All three models show the
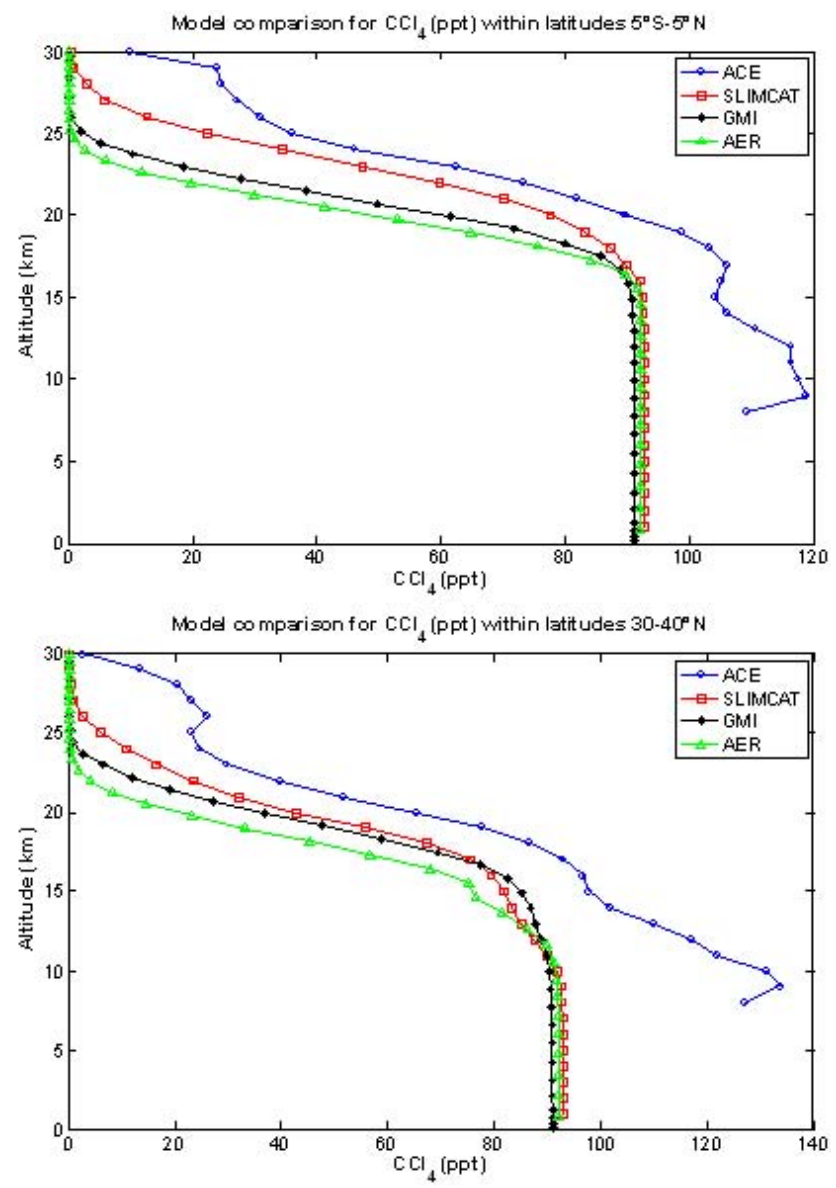

Fig. 9. The average mixing ratio of carbon tetrachloride as a function of altitude for the AER (green line with triangles), GMI (black line with asterisks) and SLIMCAT (red line with squares) models compared with the average ACE profile (blue line with circles) between the latitudes (a) $5^{\circ} \mathrm{S}-5^{\circ} \mathrm{N}$ and (b) $30-40^{\circ} \mathrm{N}$.

same basic distribution with a well-mixed troposphere and carbon tetrachloride decreasing with height in the stratosphere. All three models show some hemispheric asymmetry, with higher concentrations in the Northern Hemisphere. The SLIMCAT model shows the greatest hemispheric difference which becomes more prominent towards the polar regions. The AER and GMI models are very comparable, as they have very similarly shaped distributions but the SLIMCAT model shows a much steeper decline in carbon tetrachloride outside of the tropics. Overall there is good general agreement for the latitudinal distribution between the models and the ACE data. However, at lower altitudes model concentrations are no higher than $90-100 \mathrm{ppt}$ (a result of the model boundary conditions) and model concentrations are then lower throughout the stratosphere below $30 \mathrm{~km}$.

Figure 9 compares the altitude profile of the averaged ACE carbon tetrachloride profile in two latitude bins with corresponding averaged model data. Focusing on areas 


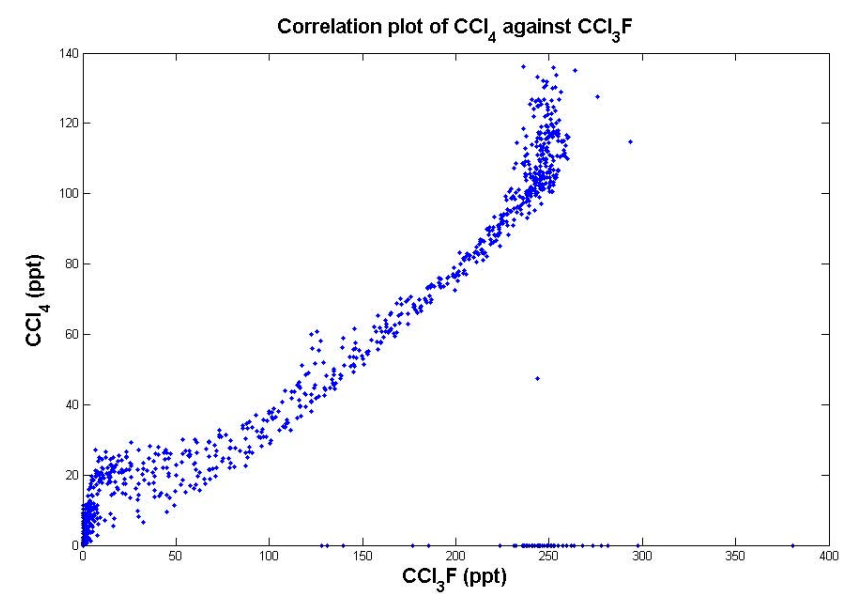

Fig. 10. Correlation plot of $\mathrm{CCl}_{4}$ VMRs with $\mathrm{CCl}_{3} \mathrm{~F}$ VMRs. The lifetime of carbon tetrachloride was estimated to be $34 \pm 5$ years from the linear part of the correlation with CFC-11.

where ACE data shows high concentrations, such as the tropics $\left(5^{\circ} \mathrm{S}-5^{\circ} \mathrm{N}\right)$ and northern mid-latitudes $\left(30-40^{\circ} \mathrm{N}\right)$, similarities can be identified. In the $5^{\circ} \mathrm{S}-5^{\circ} \mathrm{N}$ tropical region (Fig. 9a) all models show good agreement with ACE data in the lower stratosphere in terms of the vertical gradient of carbon tetrachloride. However, the models differ considerably in the troposphere below $15 \mathrm{~km}$. A similar effect is seen at mid latitudes $30-40^{\circ} \mathrm{N}$ (Fig. 9b) with the models having similar vertical gradients between 15 and $25 \mathrm{~km}$ but a tropospheric mixing ratio constrained to lower values than observed by ACE. The discrepancies observed in the troposphere are due to the imposed surface boundary concentration values used to constrain the models, thus values will be no greater than the ground input value. The models assume a uniform surface boundary condition with no latitudinal or longitudinal variation, due to the longevity of carbon tetrachloride, however, asymmetric emissions could lead to some variations. In all three models the sources and sinks are the same. They include loss of carbon tetrachloride by photolysis and reaction with $\mathrm{O}\left({ }^{1} \mathrm{D}\right)$ but no other sink mechanisms, such as ocean uptake. Differences in the modelled vertical profiles are due to different rates of stratospheric transport (Brewer-Dobson circulation).

The stratospheric lifetime of carbon tetrachloride can be estimated using tracer-tracer correlations with species of known lifetimes (Plumb and Ko, 1992). Using Eq. (1) and the method reported by Barkley et al. (2008) for carbonyl sulphide (OCS) from ACE, the stratospheric lifetime of carbon tetrachloride was estimated by correlation with CFC11 and CFC-12. Coincident CFC-11 and CFC-12 measurements were used because their stratospheric lifetimes are well known (Volk et al., 1997). The plot of carbon tetrachloride against the tracer should provide a linear correlation between the two gases in the lower stratosphere (Fig. 10). From this correlation if the lifetime is known for one of the gases, then the lifetime of the other species can be estimated (Plumb and Ko, 1992) using Eq. (1),

$\frac{\tau_{1}}{\tau_{2}}=\frac{d \sigma_{2}}{d \sigma_{1}} \frac{\sigma_{1}}{\sigma_{2}}$,

where $\tau_{1}$ and $\tau_{2}$ are the lifetimes and $\sigma_{1}$ and $\sigma_{2}$ the VMRs. The slope of the correlation is $\mathrm{d} \sigma_{2} / \mathrm{d} \sigma_{1}$. The steady state lifetimes used in equation 1 for CFC-11 and CFC-12 were $45 \pm 7$ and $87 \pm 17$ years, respectively (Volk et al., 1997). The estimated lifetime given for carbon tetrachloride by plotting against CFC-11 was approximately $34 \pm 5$ years whilst plotting carbon tetrachloride against CFC-12 gave a value close to $32 \pm 7$ years for the lifetime. The correlation with CFC-11 (Fig. 10) is much more satisfactory than for CFC-12 which shows more curvature; we therefore place more confidence in the value obtained using CFC-11. These estimates are similar to numbers reported in previously published work. Volk et al. (1997) estimated the steady state lifetime of carbon tetrachloride as $32 \pm 6$ years. Early estimates for the lifetime of carbon tetrachloride were between 30-50 years (Singh et al., 1976; Simmonds et al., 1988) before Montzka et al. (1999) and the 1998 WMO report (1999) reduced this to 35 years. Inclusion of an ocean sink (Yvon-Lewis and Butler, 2002) for carbon tetrachloride in the 2002 WMO report (2003) further reduced the lifetime to 26 years and suggestions of a soil sink (Happell and Roche, 2003) give a lifetime of only 20 years. A similar correlation plot between CFC-11 and carbon tetrachloride outputs from the SLIMCAT model gave a lifetime of $38 \pm 5$ years (not shown) whilst the AER and GMI models were just over 40 years.

\section{Summary and conclusion}

The first near global distribution of carbon tetrachloride has been obtained from 8703 ACE occultation measurements covering altitudes from 8 to $30 \mathrm{~km}$ over 30 latitude bins covering $70^{\circ} \mathrm{S}-80^{\circ} \mathrm{N}$. Low altitude carbon tetrachloride VMRs are estimated to be between 100 and $130 \mathrm{ppt}$, somewhat higher than in situ observations. Tropospheric VMRs were highest at latitudes corresponding to industrialised regions $\left(20-45^{\circ} \mathrm{N}\right)$, and near the Equator.

There appears to be only a small hemispheric asymmetry, except for the polar regions where the VMR is significantly lower in the Antarctic. There is good general agreement between model predictions and experimental data. The vertical gradient of the model VMR profiles agree well with ACE data in the lower stratosphere $(15-25 \mathrm{~km})$, although standard halocarbon scenarios used to constrain stratospheric models (e.g. WMO 2007) give boundary conditions smaller than retrieved from ACE. The stratospheric lifetime of carbon tetrachloride is estimated to be $34 \pm 5$ years from the carbon tetrachloride-CFC-11 tracer-tracer correlation. The WMO report (2007) suggests that the atmospheric lifetime and budget of carbon tetrachloride are still poorly understood. Global satellite measurements, such as these profile 
retrievals from ACE, provide a dataset that will lead to an improved understanding of the carbon tetrachloride budget.

Acknowledgements. Funding to operate the ACE mission is provided primarily by the Canadian Space Agency. We would also like to thank the UK Natural Environment Research Council (NERC) and the National Centre for Earth Observation (NCEO) for financial support. Work at the Jet Propulsion Laboratory, California Institute of Technology, was done under contract with the National Aeronautics and Space Administration (NASA). We thank S. Strahan for help with GMI model data. AER acknowledges support from the NASA ACMAP program.

Edited by: P. Monks

\section{References}

Altshuller, A. P.: Average Tropospheric Concentration of Carbon Tetrachloride Based on Industrial Production, Usage, and Emissions, Environ. Sci. Technol., 10(6), 596-598, 1976.

Barkley, M. P., Palmer, P. I., Boone, C. P., Bernath, P. F., and Suntharalingam, P.: Global distributions of carbonyl sulfide in the upper troposphere and stratosphere, Geophys. Res. Lett., 35, L14810, doi:10.1029/2008GL034270, 2008.

Bernath, P. F., McElroy, C. T., Abrams, M. C., et al.: Atmospheric Chemistry Experiment (ACE): Mission Overview, Geophys. Res. Lett., 32, L15S01, doi:10.1029/2005GL022386, 2005.

Blake, D. R., Chen, T.-Y, Smith Jr., T. W., Wang, C. J.- L, Wingenter, O. W., Blake, N. J., Rowland, F. S., and Meyer E. W.: Three-dimensional distribution of nonmethane hydrocarbons and halocarbons over the northwestern Pacific during the $1991 \mathrm{~Pa}-$ cific Exploratory Mission (PEM-West A), J. Geophys. Res., 101, 1763-1778, 1996.

Blake, N. J., Blake, D. R., Simpson, I. J., et al.: NMHCs and halocarbons in Asian continental outflow during the Transport and Chemical Evolution over the Pacific (TRACE-P) Field Campaign: Comparison With PEM-West B, J. Geophys. Res., 108, 8806, doi:10.1029/2002JD003367, 2003.

Boone, C. D., Nassar, R., Walker, K. A., Rochon, Y., McLeod, S. D., Rinsland, C. P., and Bernath, P. F.: Retrievals for the Atmospheric Chemistry Experiment Fourier Transform Spectrometer, Appl. Opt., 44, 7218-7231, 2005.

Boone, C. D., Walker, K. A., and Bernath, P. F.: Speed-dependent Voigt profile for water vapour in infrared remote sensing applications, J. Quant. Spectrosc. Rad. T., 105, 525-532, 2007.

Brenninkmeijer, C. A. M., Crutzen, P. J., Fischer, H., Gsten, H., Hans, W., Heinrich, G., Heintzenberg, J., Hermann, M., Immelmann, T., Kersting, D., Maiss, M., Nolle, M., Pitscheider, A., Pohlkamp, H., Scharffe, D., Specht, K., and Wiedensohler, A.: CARIBIC: Civil Aircraft for Global Measurement of Trace Gases and Aerosols in the Tropopause Region, J. Atmos. Ocean. Tech., 16, 1373-1383, 1999.

Brenninkmeijer, C. A. M., Crutzen, P., and Boumard, F.: Civil aircraft for the regular investigation of the atmosphere based on an instrumented container: the new CARIBIC system, Atmos. Chem. Phys., 7, 4953-4976, 2007, http://www.atmos-chem-phys.net/7/4953/2007/.
Brown, L. R., Gunson, M. R., Toth, R. A., Irion, F. W., Rinsland, C. P., and Goldman, A.: 1995 Atmospheric Trace Molecule Spectroscopy (ATMOS) linelist, Appl. Opt., 35, 2828-2848, 1996.

Butler, J. H., Battle, M., Bender, M. L., Montzka, S. A., Clarke, A. D., Saltzmank, E. S., Sucher, C. M., Severinghaus, J. P., and Elkins, J. W.: A record of atmospheric halocarbons during the twentieth century from polar firn air, Nature, 399, 749-755, 1999.

Chang, A. Y., Salawitch, R. J., Michelsen, H. A., et al.: A comparison of measurements from ATMOS and instruments aboard the ER-2 aircraft: Halogenated gases, Geophys. Res. Lett., 23, 2393-2396, 1996.

Chipperfield, M. P.: Multiannual Simulations with a ThreeDimensional Chemical Transport Model, J. Geophys. Res., 104, 1781-1805, 1999.

Chipperfield, M. P.: New Version of the TOMCAT/SLIMCAT OffLine Chemical Transport Model: Intercomparison of Stratospheric Tracer Experiments, Q. J. Roy. Meteor. Soc., 132, 11791203, doi:10.1256/qj.05.51, 2006.

Davies, T., Cullen, M. J. P., Malcolm, A. J., Mawson, M. H., Staniforth, A., White, A. A., and Wood, N.: A new dynamical core for the Met Office's global and regional modelling of the atmosphere, Q. J. Roy. Meteor. Soc., 131, 1759-1782, 2005.

Farman, J. C., Gardiner, B. G., and Shanklin, J. D.: Large losses of total ozone in Antarctica reveal seasonal $\mathrm{ClO}_{\mathrm{x}} / \mathrm{NO}_{\mathrm{x}}$ interaction, Nature, 315, 207-210, 1985.

Feng, W., Chipperfield, M. P., Dorf, M., Pfeilsticker, K., and Ricaud, P.: Mid-latitude Ozone Changes: Studies with a 3-D CTM Forced by ERA-40 Analyses, Atmos. Chem. Phys., 7, 23572369, 2007, http://www.atmos-chem-phys.net/7/2357/2007/.

Fleming, E. L., C. H. Jackman, R. S. Stolarski, and Considine, D. B.: Simulation of stratospheric tracers using an improved empirically-based two-dimensional model transport formulation, J. Geophys. Res., 104, 23911-23934, 1999.

Forster, P., Ramaswamy, V., Artaxo, P., Berntsen, T., Betts, R., Fahey, D. W., Haywood, J., Lean, J., Lowe D. C., Myhre, G., Nganga, J., Prinn, R., Raga, G., Schulz, M., and Van Dorland, R.: Changes in Atmospheric Constituents and in Radiative Forcing. In: Climate Change 2007: The Physical Science Basis. Contribution of Working Group I to the Fourth Assessment Report of the Intergovernmental Panel on Climate Change, edited by: Solomon, S., Qin, D., Manning, M., Chen, Z., Marquis, M., Averyt, K. B., Tignor, M., and Miller, H. L., Cambridge University Press, Cambridge, UK and New York, NY, USA, 2007.

Galbally, I. E.: Man-Made Carbon Tetrachloride in the Atmosphere, Science, 193, 573-576, 1976.

Happell, J. D. and Roche, M. P.: Soils: A global sink of atmospheric carbon tetrachloride, Geophys. Res. Lett., 30, 1088, doi:10.1029/2002GL015957, 2003.

Kochel, J.-M., Hartmann, J.-M., Camy-Peyret, C., Rodrigues, R., and Payan, S.: Influence of line mixing on absorption by $\mathrm{CO} 2$ $\mathrm{Q}$ branches in atmospheric balloon-borne spectra near $13 \mu \mathrm{m}, \mathrm{J}$. Geophys. Res., 102, 12891-12899, 1997.

Lovelock J. E. and Maggs R. J.: Halogenated Hydrocarbons in and over the Atlantic, Nature, 241, 194-196, 1973.

Manney, G. L., Daffer, W. H., Zawodny, J. M., Bernath, P. F., Hoppel, K. W., Walker, K. A., Knosp, B.W., Boone, C., Remsberg, E. E., Santee, M. L., Harvey, V. L., Pawson, S., Jackson, D. R., Deaver, L., McElroy, C. T., McLinden, C. A., Drum- 
mond, J. R., Pumphrey, H. C., Lambert, A., Schwartz, M. J., Froidevaux, L., McLeod, S., Takacs, L. L., Suarez, M. J., Trepte, C. R., Cuddy, C. D., Livesey, N. J., Harwood, R. S., and Waters, J. W.: Solar occultation satellite data and derived meteorological products: Sampling issues and comparisons with Aura Microwave Limb Sounder, J. Geophys. Res., 112, D24S50, doi:10.1029/2007JD008709, 2007

Martinerie, P., Nourtier-Mazauric, E., Barnola, J.-M., Sturges, W. T., Worton, D. R., Atlas, E., Gohar, L. K., Shine, K. P., and Brasseur, G. P.: Long-lived halocarbon trends and budgets from atmospheric chemistry modelling constrained with measurements in polar firn, Atmos. Chem. Phys., 9, 3911-3934, 2009, http://www.atmos-chem-phys.net/9/3911/2009/.

Molina, M. J. and Rowland, F. S.: Stratospheric sink for chlorofluoromethanes: chlorine atom-catalysed destruction of ozone, Nature, 249, 810-812, 1974.

Moore, F. L., Elkins, J. W., Ray, E. A., et al.: Balloonborne in situ gas chromatograph for measurements in the troposphere and stratosphere, J. Geophys. Res., 108, 8330, doi:10.1029/2001JD000891, 2003.

Montzka, S. A., Butler, J. H., Elkins, J. W., Thompson, T. M., Clarke, A. D., and Lock, L. T.: Present and future trends in the atmospheric burden of ozone-depleting halogens, Nature, 398, 690-694, 1999.

Nassar, R., Bernath, P. F., Boone, C. D., Manney, G. L., McLeod, S. D., Rinsland, C. P., Skelton, R., and Walker, K. A.: ACE-FTS measurements across the edge of the winter 2004 Arctic vortex, Geophys. Res. Lett., 32, L15S05, doi:10.1029/2005GL022671, 2005.

Nassar, R., Bernath, P. F., Boone, C. D., Clerbaux, C., Coheur, P. F., Dufour, G., Froidevaux, L., Mahieu, E., McConnell, J. C., McLeod, S. D., Murtagh, D. P., Rinsland, C. P., Semeniuk, K., Skelton, R., Walker, K. A., and Zander, R.: A global inventory of stratospheric chlorine in 2004, J. Geophys. Res., 111, D22312, doi:10.1029/2006JD007073, 2006.

Nemtchinov, V. and Varanasi, P.: Thermal infrared absorption crosssections of $\mathrm{CCl}_{4}$ needed for atmospheric remote sensing, J. Quant. Spectrosc. Rad. T., 82, 473-481, 2003.

Palmer, P. I., Jacob, D. J., Mickley, L. J., Blake, D. R., Sachse, G. W., Fuelberg, H. E., and Kiley, C. M.: Eastern Asian emissions of anthropogenic halocarbons deduced from aircraft concentration data, J. Geophys. Res., 108, 4753, doi:10.1029/2003JD003591, 2003.

Prinn, R. G., Weiss, R. F., Fraser, P. J., et al.: A history of chemically and radiatively important gases in air deduced from ALE/GAGE/AGAGE, J. Geophys. Res., 105, 17751-17792, 2000.

Plumb, R. A. and Ko, M. K. W.: Interrelationships between mixing ratios of long-lived stratospheric constituents, J. Geophys. Res., 97, 10145-10156, 1992.

Romashkin, P. A., Hurst, D. F., Elkins, J. W., Dutton, G. S., Fahey, D. W., Dunn, R. E., Moore, F. L., Myers, R. C., and Hall, B. D.: In Situ Measurements of Long-Lived Trace Gases in the Lower Stratosphere by Gas Chromatography, J. Atmos. Ocean. Technol., 18, 1195-1204, 2000.

Rothman, L. S., Jacquemarta, D., Barbe, A., et al.: The HITRAN 2004 molecular spectroscopic database, J. Quant. Spectrosc. Rad. T., 96, 139-204, 2005.

Sander, S. P., Finlayson-Pitts, B. J., Friedl, R. R., Golden, D. M.,
Huie, R. E., Keller-Rudek, H., Kolb C. E., Kurylo, M. J., Molina, M. J., Moortgat, G. K., Orkin, V. L., Ravishankara, A. R., and Wine, P. H.: Chemical kinetics and photochemical data for use in atmospheric studies, evaluation number 15, JPL Publication 06-2, Jet Propulsion Laboratory, Pasadena, USA, 2006.

Simmonds, P. G., Cunnold, D. M., Alyea, F. N., Cardelino, C. A., Crawford, A. J., Prinn, R. G., Fraser, P. J., Rasmussen, R. A., and Rosen, R. D.: Carbon Tetrachloride Lifetimes and Emissions Determined from Daily Global Measurements During 1978-1985, J. Atmos. Chem., 7, 35-58, 1988.

Simmonds, P. G., Cunnold, D. M., Weiss, R. F., Miller, B. R., Prinn, R. G., Fraser, P. J., McCulloch, A., Alyea, F. N., and O'Doherty, S.: Global trends and emission estimates of $\mathrm{CCl} 4$ from in situ background observations from July 1978 to June 1996, J. Geophys. Res., 103, 16017-16027, 1998.

Singh, H. B., Fowler, D. P., and Peyton, T. O.: Atmospheric Carbon Tetrachloride: Another Man-Made Pollutant, Science, 192, 1231-1234, 1976.

Solomon, S., Qin, D., Manning, M., Alley, R. B., Berntsen, T., Bindoff, N. L., Chen, Z., Chidthaisong, A., Gregory, J. M., Hegerl, G. C., Heimann, M., Hewitson, B., Hoskins, B. J., Joos, F., Jouzel, J., Kattsov, V., Lohmann, U., Matsuno, T., Molina, M., Nicholls, N., Overpeck, J., Raga, G., Ramaswamy, V., Ren, J., Rusticucci, M., Somerville, R., Stocker, T. F., Whetton, P., Wood, R. A., and Wratt, D.: 2007: Technical Summary. In: Climate Change 2007: The Physical Science Basis. Contribution of Working Group I to the Fourth Assessment Report of the Intergovernmental Panel on Climate Change, edited by: Solomon, S., Qin, D., Manning, M., Chen, Z., Marquis, M., Averyt, K. B., Tignor, M., and Miller, H. L., Cambridge University Press, Cambridge, United Kingdom and New York, NY, USA, 2007.

Strahan, S. E., Duncan, B. N., and Hoor, P.: Observationally derived transport diagnostics for the lowermost stratosphere and their application to the GMI chemistry and transport model, Atmos. Chem. Phys., 7, 2435-2445, 2007,

http://www.atmos-chem-phys.net/7/2435/2007/.

Sturrock, G. A., Etheridge, D. M., Trudinger, C. M., Fraser, P. J., and Smith, A. M.: Atmospheric histories of halocarbons from analysis of Antarctic firn air: Major Montreal Protocol species, J. Geophys. Res., 107, 4765, doi:10.1029/2002JD002548, 2002.

Swinbank, R. and O'Neill, A.: A stratosphere-troposphere data assimilation system, Mon. Weather Rev., 122, 686-702, 1994.

Swinbank, R., Ingleby, N. B., Boorman, P. M., and Renshaw, R. $\mathrm{J} .:$ A 3D variational data assimilation system for the stratosphere and troposphere, Tech. Rep. 71, Met Office Numerical Weather Prediction Forecasting Research Scientific Paper, 2002.

Toon, G. C.: The JPL MkIV Interferometer, Optics and Photonics News, 2, 19-21, 1991.

Toon, G. C., Blavier, J. F., Sen, B., et al.: Comparison of MkIV balloon and ER-2 aircraft measurements of atmospheric trace gases, J. Geophys. Res., 104, 26779-26790, 1999.

United Nations Environment Programme, Montreal Protocol on Substances that Deplete the Ozone Layer, UNEP, 1987, http:// www.unep.ch/ozone/mont_t.htm, last amended September 1997.

Velders, G. J. M., Andersen, S. O., Daniel, J. S., Fahey, D. W., and McFarland, M.: The importance of the Montreal Protocol in protecting climate, PNAS, 104, 4814-4819, 2007.

Volk, C. M., Elkins, J. W., Fahey, D. W., Dutton, G. S., Gilligan, J. M., Loewenstein, M., Podolske, J. R., Chance, K. R., and Gun- 
son, M. R.: Evaluation of source gas lifetimes from stratospheric observations, J. Geophys. Res., 102, 25543-25564, 1997.

Weisenstein, D. K., Yue, G. K., Ko, M. K. W., Sze, N.-D., Rodriguez, J. M., and Scott, C. J.: A two-dimensional model of sulfur species and aerosols, J. Geophys. Res., 102, 13019-13035, 1997.

World Meteorological Organization (WMO): Scientific Assessment of Ozone Depletion:1998, Geneva, Switzerland, 1999.

World Meteorological Organization (WMO): Scientific Assessment of Ozone Depletion: 2002, Geneva, 2003.
World Meteorological Organisation (WMO): Scientific Assessment of Ozone Depletion: 2006, Geneva, Switzerland, 2007.

Yvon-Lewis, S. A. and Butler, J. H.: The effect of oceanic uptake on the atmospheric lifetime of selected trace gases, J. Geophys. Res., 107, 4414, doi:10.1029/2001JD001267, 2002.

Zhou, D. K., Bingham, G. E., Anderson, G. P., and Nadile, R. M.: CIRRIS-1A measurements of stratospheric carbon tetrachloride $\left(\mathrm{CCl}_{4}\right)$ and carbon tetrafluoride $\left(\mathrm{CF}_{4}\right)$, Geophys. Res. Lett., 25 , 325-328, 1998. 